\title{
Short-Term Outcomes and Mortality of Late Preterm Infants
}

\author{
Cahide Bulut, Tuğba Gürsoy, Fahri Ovalı
}

Neonatal Intensive Care Unit, Zeynep Kamil Maternity and Children's Diseases Training and Research Hospital, İstanbul, Turkey

\begin{abstract}
Background: Late preterm infants have increased rates of morbidity and mortality compared to term infants. Determining the risk factors in these infants leads to more comprehensive preventive and treatment strategies.

Aims: Our aim was to analyse the morbidity rates such as respiratory system diseases, infections, congenital anomalies, hypoglycemia and hematologic abnormalities and mortality rates in a large group of patients at a referral center.

Study Design: Retrospective cross-sectional study. Methods: Medical records of late preterm and term infants who were managed at the referral center were analysed.
\end{abstract}

Results: 41752 births were analysed in 3 years. $71.9 \%$ of all births were between 37-42 gestational weeks (i.e. term) and $16.1 \%$ were between $34-37$ weeks (i.e. late preterm). Compared to term infants, late preterm infants had increased rates of short-term problems. The rate of mortality increased with decreased gestational age. The duration of hospitalization was significantly higher in the smallest late preterm infants.

Conclusion: This study demonstrated the need that late preterm infants who have higher risk for morbidity and mortality, compared to term infants require close monitoring. The rate of mortality and hospitalization increased with decreased gestational age.

Keywords: Late preterm, outcome, morbidity
Preterm birth rates are on the increase all over the world and continue to be an important cause for neonatal mortality and morbidity. Although clinical investigations and statistics have traditionally focused on premature infants born at a gestational age of 32 weeks or less, this increase is related to the increase in late preterm births and compared to term births, late preterms have increased risk of mortality and morbidity (1). National Institute of Child Health and Human Development (NICHHD) defines late preterm births as births between $34^{0 / 7}$ to $36^{6 / 7}$ weeks (2). These infants are usually considered to be developmentally and functionally as mature as term newborns and both obstetricians and neonatologists tend to consider these newborns to be protected from common perinatal problems. However, late preterm infants are more likely to develop problems such as respiratory distress, apnea, feeding intolerance, hyperbilirubinemia, hypoglycemia and hypothermia (3). Moreover, the prevalance of these problems may be different in each country. Therefore, determining the risk factors in these infants leads to more com- prehensive preventive and treatment strategies. Late preterm infants who have potentially higher risk for morbidity and hospitalization require closer monitoring and follow-up. In order to understand their needs better, we aimed to analyse the rate of late preterm births among a large cohort of births and determine risk factors as well as mortality and short term outcomes.

\section{MATERIALS AND METHODS}

This study was conducted at a large referral hospital during the years $2008-2010$ for a 3 -year period. This hospital is one of the biggest maternity hospitals in the country and sees approximately 10000 births and 2000 neonatal intensive care unit (NICU) admissions annually. Demographical and clinical data were retrieved from the patients' medical records.

Medical records of all infants born in the hospital were evaluated. Babies who were between $34^{0 / 7}$ to $36^{6 / 7}$ weeks and

Address for Correspondence: Dr. Fahri Oval, Neonatal Intensive Care Unit, Zeynep Kamil Maternity and Children's Diseases Training and Research Hospital, İstanbul, Turkey Phone: +90 5324116715 e-mail: fovali@yahoo.com

Received: 7 January 2015 Accepted: 27 October $2015 \cdot$ DOI: 10.5152/balkanmedj.2016.16721

Available at www.balkanmedicaljournal.org 
admitted to the NICU for any reason were compared with term infants (i.e. $37^{0 / 7}$ to $41^{6 / 7}$ gestational weeks). According to our hospital policy, infants with a weight of greater than 2000 grams are followed in the mother's room and monitored for short- term complications. Infants who are deemed to have no medical problems, and have succeeded in postnatal adaptation are discharged with an arranged follow-up visit within the next 24-48 hours. Term infants who had been admitted to the NICU for respiratory distress, temperature instability, hypoglycemia, jaundice, poor feeding, sepsis, polycythemia, dehydration or congenital anomalies were recruited for comparison. Late preterm infants were further stratified for each gestational week (i.e. $34^{0 / 7}$ to $34^{6 / 7} ; 35^{0 / 7}$ to $35^{6 / 7}$ and $36^{0 / 7}$ to $36^{6 / 7}$ ) and analysed for rates of mortality and short-term outcomes. Respiratory distress syndrome was defined as tachypnea and intercostal retractions with or without grunting, necessitating the administration of supplemental oxygen or ventilatory support coupled with roentgenographic findings of decreased aerization or ground glass appearance; transient tachypnea of the newborn was defined as mild respiratory distress and tachypnea lasting for at most 48 hours and does not necessitate assisted ventilation methods coupled with radiographic findings of perihilar steraking, fissure edema and congestion; meconium aspiration syndrome was defined as presence of meconium in the amniotic fluid, coupled with respiratory symptoms and typical radiological appearence of the lung; pneumonia was defined as respiratory symptoms with typical radiological lung findings (4); sepsis was defined any culture-proven infection; meningitis was defined any bacterial growth in the cerebrospinal fluid; temperature instability was defined as any body temperature below $35.0^{\circ} \mathrm{C}$ or above $37.9^{\circ} \mathrm{C}(5)$; jaundice was defined any hyperbilirubinemia above the age-spesific threshold level of bilirubin necessitating phototherapy or exchange transfusion (6); hypoglycemia was defined as a blood sugar $<47 \mathrm{mg} / \mathrm{dL}$; polycythemia was defined as a hematocrit of $>0.65$ (7).

The data were analysed using SPSS ver. 16.0 (IBM Corporation; New York, USA). The variables were investigated using visual (histograms, probability plots) and analytical methods (Kolmogorov-Simirnov test) to determine whether or not they were normally distributed. Descriptive analyses were presented using means and standart deviations for mormally distributed variables and median $(25 \%$ - $75 \%)$ for the variables not normally distributed. Student's t-test was used to compare normally distributed variables and Mann Whithey$\mathrm{U}$ test was used otherwise. Kruskal Wallis test was used for nonparametric variables when there were more than 2 groups. Cross tables were performed for categoric variables and these variables were compared using Chi-square test. A $p$ value of less than 0.05 was considered to be statistically significant.

This study was approved by the Ethical Committee of our hospital. Written informed consent was obtained from the parents of the patients during the hospitalization period.

\section{RESULTS}

During the study period, there were 41752 births in the hospital which included 30055 (71.9\%) term, 11273 (27\%) preterm and $459(1,1 \%)$ post-term infants. Late preterm infants constituted $59.9 \%(\mathrm{n}=6741)$ of all preterm infants. 1179 (17.5\%) of late preterm infants and 1941 (6.5\%) of term infants were admitted to the NICU $(p=0.001)$. Gestational age, birth weight, and rate of gestational diabetes were significantly lower in late preterm infants, whereas rate of cesarean section, number of males, perinatal asphyxia, premature rupture of membranes and preeclampsia were significantly higher in late preterms compared to term ones. Only the rate of oligohydramnios, did not reach significant difference. Demographic data for the study population are shown in Table 1 .

The main reason for admission was respiratory distress for late preterm infants (39.4\%). Of these infants, $403(34.2 \%)$ had transient tachypnea of the newborn; 52 (4.4\%) had pneumonia and $9(0.8 \%)$ had meconium aspiration syndrome. Late preterm infants had higher risk for perinatal morbidities except for meningitis, indirect hyperbilirubinemia, and congenital anomalies. Mortality did not change among the infants who were hospitalized. The morbidites of hospitalized infants are shown on Table 2. The median hospitalization duration of late preterm infants was 7 days (4-11 days) whereas it was 4 (2-8) days for term infants $(\mathrm{p}<0.001)$.

The most prevalant cause of death in late preterm infants was respiratory distress, followed by congenital anomalies, which was the main cause of death in term infants. Death from

TABLE 1. Demographic data of late preterm and term infants admitted to the NICU

\begin{tabular}{lccc}
\hline & $\begin{array}{c}\text { Late preterm } \\
\text { infants }(\mathrm{n}=1179)\end{array}$ & $\begin{array}{c}\text { Term infants } \\
(\mathrm{n}=1941)\end{array}$ & $\mathrm{p}$ \\
\hline Gestational age (weeks) mean \pm SD & $35.1 \pm 0.8$ & $38.9 \pm 1.3$ & $<0.001$ \\
Male, $\mathrm{n}(\%)$ & $652(55.3)$ & $988(50.9)$ & 0.017 \\
Birthweight (g) mean \pm SD & $2246 \pm 514$ & $3083 \pm 625$ & $<0.001$ \\
Cesarean section, $\mathrm{n}(\%)$ & $704(59.7)$ & $631(32.5)$ & $<0.001$ \\
Premature rupture of membranes, $\mathrm{n}(\%)$ & $104(8.8)$ & $66(3.4)$ & $<0.001$ \\
Oligohydramnios, $\mathrm{n}(\%)$ & $33(2.8)$ & $39(2.0)$ & 0.15 \\
Preeclampsia, $\mathrm{n}(\%)$ & $99(8.4)$ & $82(4.2)$ & $<0.001$ \\
Gestational diabetes, $\mathrm{n}(\%)$ & $42(3.6)$ & $103(5.3)$ & 0.025 \\
Perinatal asphyxia, $\mathrm{n}(\%)$ & $38(3.2)$ & $32(1.6)$ & 0.002 \\
\hline
\end{tabular}

NICU: neonatal intensive care unit; SD: standart deviation; g: grams 
TABLE 2. Mortality and morbidity rates of late preterm and term infants admitted to the NICU

\begin{tabular}{lccc}
\hline & $\begin{array}{c}\text { Late preterm } \\
\mathrm{N}=1179\end{array}$ & $\begin{array}{c}\text { Term } \\
\mathrm{N}=1941\end{array}$ & $\mathrm{p}$ \\
\hline Length of stay in hospital (days) & $7(4-11)$ & $4(2-8)$ & $<0.001$ \\
Respiratory distress, $\mathrm{n}(\%)$ & $403(34.2 \%)$ & $292(15 \%)$ & $<0.001$ \\
Pneumonia, n (\%) & $52(4.4 \%)$ & $39(2 \%)$ & $<0.001$ \\
Meconium aspiration syndrome, $\mathrm{n}(\%)$ & $9(0.8 \%)$ & $46(2.4 \%)$ & $<0.001$ \\
Sepsis, n (\%) & $249(21.1 \%)$ & $216(11.1 \%)$ & $<0.001$ \\
Meningitis, n (\%) & $6(0.5 \%)$ & $3(0.2 \%)$ & $\mathrm{NS}(0.07)$ \\
Indirect hyperbilirubinemia, n (\%) & $567(48.1 \%)$ & $898(46.3 \%)$ & $\mathrm{NS}(0.32)$ \\
Hypoglycemia, n (\%) & $180(15.3 \%)$ & $147(7.6 \%)$ & $<0.001$ \\
Thrombocytopenia, $\mathrm{n}(\%)$ & $100(8.5 \%)$ & $9(0.5 \%)$ & $<0.001$ \\
Congenital anomalies, $\mathrm{n}(\%)$ & $114(9.7 \%)$ & $230(11.8 \%)$ & $\mathrm{NS}(0.06)$ \\
Mortality & $59(5 \%)$ & $77(4 \%)$ & $\mathrm{NS}(0.17)$ \\
\hline NICU: neonatal intensive care unit & & &
\end{tabular}

TABLE 3. The causes of mortality

\begin{tabular}{lccc}
\hline & Late preterm & Term & $\mathrm{p}$ \\
\hline Respiratory distress, $\mathrm{n}(\%)$ & $37(62.7)$ & $7(9.1)$ & $<0.001$ \\
Pneumonia, $\mathrm{n}(\%)$ & $9(15.3)$ & $4(5.2)$ & 0.047 \\
Meconium aspiration syndrome, n (\%) & $2(3.4)$ & $9(11.7)$ & NS $(0.07)$ \\
Perinatal asphyxia, $\mathrm{n}(\%)$ & $15(25.4)$ & $8(10.4)$ & 0.02 \\
Sepsis, $\mathrm{n}(\%)$ & $29(49.2)$ & $13(16.9)$ & $<0.001$ \\
Congenital anomalies, $\mathrm{n}(\%)$ & $36(61)$ & $49(63.6)$ & $\mathrm{NS}(0.7)$ \\
Other causes, $\mathrm{n}(\%)$ & $13(22.1)$ & $7(9.1)$ & \\
\hline
\end{tabular}

TABLE 4. Hospitalization and death rates of all late preterm and term infants born in that period of time

\begin{tabular}{lccccc}
\hline Gestational week & $\begin{array}{c}34-34^{677} \\
(\mathrm{n}=1534)\end{array}$ & $\begin{array}{c}35-35^{67} \\
(\mathrm{n}=2232)\end{array}$ & $\begin{array}{c}36-36^{67} \\
(\mathrm{n}=2976)\end{array}$ & $\begin{array}{c}37-42 \\
(\mathrm{n}=30055)\end{array}$ & $\mathrm{p}$ \\
\hline Hospitalization, $\mathrm{n}(\%)$ & $423(27.5)$ & $426(19)$ & $330(11)$ & $1942(6.5)$ & $<0.001$ \\
Mortality, n (\%) & $22(1.4)$ & $19(0.85)$ & $18(0.6)$ & $77(0.25)$ & $<0.001$ \\
$\begin{array}{l}\text { Duration of hospitalization } \\
\text { (days) }\end{array}$ & $8(5-12)$ & $6(4-11)$ & $7(4-10)$ & $4(2-8)$ & $<0.001$ \\
\hline
\end{tabular}

respiratory distress, pneumonia, perinatal asphyxia and sepsis were significantly higher in late preterm infants, whereas death from meconium aspiration syndrome and congenital anomalies were similar in both groups (Table 3).

The rate of hospitalization $(27.5 \%, 19 \%, 11 \%$ and $6.5 \%$ in $34,35,36$ and $37-42$ weekers respectively) and overall mortality $(1.4 \%, 0.85 \%, 0.6 \%$ and $0.25 \%$ in $34,35,36$, and $37-42$ weekers respectively) increased with decreasing gestational age (Table $4, \mathrm{p}<0.001$ ). The duration of hospitalization was higher in the smallest late preterm infants and it also increased with decreasing gestational age $(\mathrm{p}<0.001)$ (Table 4$)$.

\section{DISCUSSION}

Preterm births constitute almost $12.8 \%$ of all births and $75 \%$ of these are late preterm births (8). The rate of births below 34 weeks has increased $10 \%$ since 1990 but the rate of late preterm births has increased almost $25 \%$ during the same period. Increased maternal age, increased use of assisted reproductive technologies and consequent multiple births as well as increased rates of induction of labor and cesarean section are all considered to have contributed to this rate (9). Late preterm infants have been traditionally considered as term infants and they have been managed in the same manner. However, studies have shown that late preterm infants are at higher risk for poor short-term outcomes including respiratory distress, hypothermia, hypoglycemia and hyperbilirubinemia as well as long-term outcomes with regard to developmental delay, school performance and social security benefits and therefore they should be approached more carefully (10).

In our study, $71.9 \%$ of all births were between $37-42$ gestational weeks and $16.1 \%$ were between $34-36^{6 / 7}$ weeks. The rate of late preterm infants among all preterms was $59.9 \%$. This rate was similar to that of Çelik et al. (11), which was $60 \%$. In a study performed in United States, this rate was found to be $71.4 \%$ (5). In a nationwide study conducted in 2008 , rate of preterm births was found to be $10 \%$ and rate of late preterm births was found to be $64 \%$ of preterm births (12). Atasay et al. (13) have reported a rate of $9.4 \%$ among 1852 infants and $58.7 \%$ among preterm births, whereas Karataş et al. (14) have reported a rate of $6.7 \%$ among all births.

Late preterm infants were more likely to be delivered by cesarean section than term infants $(59.7 \%$ vs. $32.5 \%)$. The indications for cesarean sections were multiple, but most frequent reasons were breech presentation, previous $\mathrm{C}$-section, multiple births, fetal distress and antepartum hemorrhage. These results were comparable to others (2). However, more research is needed to refine the management of the fetus and mother at late preterm gestation.

Obstetric complications such as preeclampsia, premature rupture of membranes, and perinatal asphxia were also significantly higher in the late preterm group. Although perinatal asphyxia is not a serious problem in our population, rate of perinatal asphyxia was twice as common in late preterm infants. This is also an expected result, as prematurity increases the risk of birth asphyxia (15). Karataş et al. (14) have reported that the most frequent reason for late preterm births was preeclampsia.

As expected, the rate of infants born to preeclamptic moth- 
ers was higher in the late preterm group. The risk of preterm delivery is not increased in patients with diabetes, however rate of NICU admissions are increased significantly due to neonatal complications (16). Karataş et al. (14) have also reported preeclampsia as the most common obstetric problem in late preterm infants. In our study, the rate of infants born to gestational diabetic mothers was higher in term infants.

Hospitalization rate of infants born to mothers with premature rupture of membranes (PROM) were 2.5 times more in late preterm infants (8.8\% vs. 3.4\%). Atasay et al. (13) have found 1.4 times increased hospitalization rate among their late preterm infants. Jackson et al. (17) have reported a similar short time outcome in late preterm infants.

Our study reveals that $17.5 \%$ of late preterm infants and $6.5 \%$ of term infants were hospitalized. In a similar study these rates were found to be $36.8 \%$ and $7.24 \%$ respectively (2). When stratified according to gestational week, hospitalization rates were also lower than those in our study $(27.5 \%$ vs. $73.9 \%$ for $34-34^{6 / 7}$ weekers; $19 \%$ vs. $43.4 \%$ for $35-35^{6 / 7}$ weekers; $11 \%$ vs. $20.9 \%$ for $36-36^{6 / 7}$ weekers). Engle et al. (18) reports NICU admission rates of $88 \%, 54 \%$ and $25 \%$ for babies born at 34, 35, 36 weeks respectively, which are pretty higher than our ratios. Femitha and Bhat (19) have reported NICU admission rates of $49.6 \%$ and $14.4 \%$ for late preterm and term infants respectively. The reason for this discrepancy is not clear but may be due to the different hospitalization policies of different centers. In fact, in our hospital, infants less than 34 weeks and less than 2000 grams are admitted routinely whereas in the other center, infants less than 35 weeks and less than 2300 grams were admitted as a hospital policy.

Respiratory disorders are the most important morbidities in late preterm infants. Transient tachypnea of the newborn, respiratory distress syndrome, pneumonia and meconium aspiration syndrome were the most frequent diagnoses, accounting for $39.4 \%$ of admissions to the NICU, compared to $19.4 \%$ in term infants. Rubaltelli et al. (20) reported that the occurence of respiratory distress was $20.6 \%$ at $33-34$ weeks and $7.3 \%$ at 35-36 weeks. These figures were $22.1 \%$ and $8.3 \%$ at Kaiser Permanente cohort (21). Kalyoncu et al. (22) have found a significantly increased rate of respiratory problems among late preterm infants compared to term infants. Transient tachypnea of the newborn was the most common diagnosis, followed by RDS and pneumonia. In the study of Atasay et al. (13), respiratory distress was seen in $30 \%$ of late preterm infants. Although our rates are slightly higher than those reported, the differences are not significant. Late preterm infants are at the saccular-alveolar stage of lung development and underdevelopment of the lung surfactant system, as well as defective fetal alveolar fluid resorption and prelabour cesarean section may have contributed to increased rate of respiratory distress (23).
As expected, meconium aspiration syndrome was higher in term infants.

The incidence of hypoglycemia in late preterm infants is reported to be 3 times that in term infants (24). In a systematic review, Teune et al. (25) have found a rate of $7.1 \%$ in late preterm infants. Laptook and Jackson (26) have stressed the increased incidence of nursery admissions in late preterem infants with hypoglycemia. In our study, hypoglycemia was twice as common in late preterm infants, which was comparable to the rates reported before $(22,27)$. The cause of hypoglycemia may be deficient hepatic gluconeogenesis, glycogenolysis, ketogenesis and lipolysis. Delayed and ineffective oral feedings may also contribute to hypoglycemia.

Infection risk is increased in preterm infants, due to immaturity of the immunological system and increased number of interventions in these infants. Compared to term and extremely preterm infants, late preterm infants are intermediate with regard to immunologic maturity. In our study, the rate of septicemia was twice as high in late preterm infants compared to term infants $(21.1 \%$ vs. $11.1 \%)$. These rates are comparable to that of Sinha et al. (28), who have showed that in infants less than 36 weeks, rate of infection is increased 3.7 times. Kalyoncu et al. (22) have reported 43 sepsis cases among 252 late preterm infants. Similarly Atasay et al. (13) have reported an infection rate of $15 \%$ among late preterm infants. Knashu et al. (29) have reported 5.2 times more infections in late preterm infants. However, rate of meningitis was not different between late preterm and term infants.

Late preterm infants are reported to have 3 to 5 times higher mortality rates than term infants (30). In our study, among late preterm infants, mortality rates were $1.4 \%, 0.9 \%, 0.6 \%$ in 34 , 35 and 36 weekers respectively and $0.3 \%$ in term infants. In a similar study in the USA, these rates were $1.1,1.5,0.5$ in late preterms and 0.20 per 1000 live births in term infants (31). Death from respiratory distress, pneumonia, perinatal asphyxia and sepsis were significantly higher in late preterm infants. The probable reasons for these increases were the early delivery of fetuses resulting in surfactant deficiency, inadvertent conditions of delivery resulting in perinatal asphyxia and longer hospitalization of late preterm infants resulting in increased rates of pneumonia and sepsis, which may be lethal. Our mortality rates in both late preterm and term infants were higher than this study but most of the infants $(60 \%)$ who died had lethal congenital anomalies. On the other hand Kalyoncu et al. (22) have reported a mortality rate of $2.3 \%$ among late preterm infants, while there was no deaths among matched term infants.

When we evaluate the mortality among hospitalized infants, there was not any difference between late preterm and term infants which might be due to the high incidence of congenital anomalies which are the main cause of death in all population. 
Fetuses with congenital anomalies are referred to our hospital too often and they usually succumb after birth, giving rise to the mortality rate. Most of these infants have antenatal diagnosis, but because of socio-cultural and religious reasons, most families deny therapeutic abortion and babies are born any way.

Although jaundice is reported to be higher in late preterm infants, our findings were similar both late preterm and term infants (32). ABO incompatibility was even higher in the term group, whereas Rh incompatilibility was similar in both groups. However, Atasay et al. (13) have reported indirect hyperbilirubinemia as the most common neonatal problem among late preterm infants at a rate of $37.5 \%$.

The limitation of our study is that, it reflects the results of a single center and the number of infants in each gestational age group who were hospitalized and who died were low. These results should be confirmed by larger studies.

Our results indicate that late preterm infants are prone to many medical short-term complications such as respiratory distress, hypoglycemia, sepsis and mortality. Obstetricians should be cautious when deciding on the timing of birth, and should not be tolerant to interrupt pregnancy when there are maternal or fetal complications after 34 gestational weeks, whereas neonatologists should not tend to keep these newborns in low-risk nurseries or rooming in care and discharge infants early (33). A discussion between the obstetrician and the neonatologist about the outcome of the mother and the fetus and the optimal timing of delivery is crucial. Since late preterm infants have increased rate of problems, they should be followed up for a longer time in the hospital or should be called for close follow-up after the first days of discharge from the hospital.

Ethics Committee Approval: Ethics committee approval was received for this study from the ethics committee of Zeynep Kamil Maternity and Children's Diseases Training and Research Hospital.

Informed Consent: Written informed consent was obtained from patients' parents who participated in this study.

Peer-review: Externally peer-reviewed.

Author contributions: Concept - T.G., F.O.; Design - T.G., F.O.; Supervision - F.O.; Resource - C.B., T.G.; Materials - C.B., T.G.; Data Collection and/or Processing - C.B., T.G.; Analysis and/or Interpretation - C.B., T.G., F.O.; Literature Search - C.B., T.G.; Writing - C.B, T.G.; Critical Reviews - F.O.

Conflict of Interest: No conflict of interest was declared by the authors.

Financial Disclosure: The authors declared that this study has received no financial support.

\section{REFERENCES}

1. Kramer MS, Demissie K, Yang HM, Platt RW, Sauve R, Liston $\mathrm{R}$ et al. The contribution of mild and moderate preterm birth to infant mortality. JAMA 2000;284:843-9. [CrossRef]

2. Raju TNK, Higgins RD, Stark AR, Leveno KJ. Optimizing care and outcome for late preterem (near-term) infants: a summary of the workshop sponsored by the NICHD. Pediatrics 2006;118:1207-14. [CrossRef]

3. Wang ML, Dorer DJ, Fleming MP, Catlin EA. Clinical outcomes of near-term infants. Pediatrics 2004;114:372-6. [CrossRef]

4. Whitsett JA, Rice WR, Warner BB, Wert SE Pryhuber GS. Acute respiratory disorders. In: MacDonald MG, Mullet MD, Seshia MMK (eds). Avery's Neonatology, $6^{\text {th }}$ ed. Philadelphia, USA, Lippincott Williams and Wilkins; 2005:pp. 569-76.

5. Edwards MS. Postnatal bacterial infections. In: Martin RJ, Fanaroff AA, Walsh MC. Fanaroff and Martin's Neonatal Perinatal Medicine. Diseases of the Fetus and Infant. $9^{\text {th }}$ ed. St. Louis, USA, Elsevier; 2011;pp. 793-830.

6. Kaplan M, Wong RJ, Sibley E, Stevenson DK. Neonatal jaundice and liver disease. In: Martin RJ, Fanaroff AA, Walsh MC. Fanaroff and Martin's Neonatal Perinatal Medicine. Diseases of the Fetus and Infant. $9^{\text {th }}$ ed. St. Louis, USA, Elsevier; 2011;pp. 1443-96. [CrossRef]

7. Luchtman-Jones L, Wilson DB. Hematologic problems in the fetus and neonate. In: Martin RJ, Fanaroff AA, Walsh MC. Fanaroff and Martin's Neonatal Perinatal Medicine. Diseases of the Fetus and Infant. $9^{\text {th }}$ ed. St. Louis, USA, Elsevier; 2011;pp. 1303-60.

8. Martin JA, Hamilton BE, Sutton PD. Births: Final data for 2006. In: National vital statistics reports; Hyattsville (MD): National Center for Health Statistics; 2009;57:p. 1-102.

9. Centers of Disease Control and Prevention National Center for Health Statistics VitalStatt. Available at: http://www.cdc.gov/ nchs/vitalstats.htm.

10. Binarbaşı P, Akın Y, Narter F, Telatar B, Polatoğlu E, Ağzıkuru T. Mortality and morbidity in late preterm newborns. Turk Arch Ped 2013;48:17-22.

11. Çelik İH, Demirel G, Canpolat FE, Dilmen U. A common problem for neonatal intensive care units: late preterm infants, a prospective study with term controls in a large perinatal center. $J$ Matern Fetal Neonatal Med 2013;26:459-62. [CrossRef]

12. Turkish Population and Health Research 2008 data. (Turkish) Available at: http://www.hips.hacettepe.edu.tr/tnsa2008/

13. Atasay B, Okulu E, Mungan Akın İ, Çandır O, Arsan S, Türmen T. The early clinical outcomes of late preterm newborns. Turkish J Pediatric Dis 2010;4:30-5.

14. Karataş A, Albayrak M, Keskin F, Bıyık I, Okur M, Güneş C, et al. Geç preterm doğum olgularında erken neonatal sonuçlar. Turk J Soc Obstet Gynecol 2013;10:165-72.

15. Lee AC, Mullany LC, Tielsch JM, Katz J, Khartry SK, LeClerq SC, et al. Risk factors for neonatal mortality due to birth asphyxia in southern Nepal. A prospective, community based cohort study. Pediatrics 2008;121:e1381-90. [CrossRef] 
16. Lee-Parritz A, Cloherty JP. Diabetes mellitus. In: Cloherty JP, Eichenwald EC, Stark AR (Eds): Manual of Neonatal care $6^{\text {th }}$ ed. Wolters Kluwer, Philadelphia 2008;pp. 9-19.

17. Jackson GL, Rawiki P, Sendelbach D, Manning MD, Engle WD. Hospital course and short term outcomes of term and late preterm neonates following exposure to prolonged rupture of membranes and/or chorioamnionitis. Pediatr Infect Dis $J$ 2012;31:89-90. [CrossRef]

18. Engle WA, Tomashek KM, Wallman C; Committee on Fetus and Newborn, American Academy of Pediatrics. "Late preterm" infants: A population at risk. Pediatrics 2007;123:1390. [CrossRef]

19. Femitha P, Bhat BV. Early neonatal outcome in late preterms. Indian J Pediatr 2012;79:1019-24. [CrossRef]

20. Rubaltelli FF, Bonafe L, Tangucci M, Spagnolo A, Dani C. Epidemiology of neonatal acute respiratory disorders. A multicenter study on incidence and fatality rates of neonatal acute respiratory disorders according to gestational age, maternal age, pregnancy complications and type of delivery. Italian Group of Neonatal Pneumology. Biol Neonate 1998;74:7-15. [CrossRef]

21. Hibbard JU, Wilkins I, Sun L, Gregory K, Haberman S, Hoffman $\mathrm{M}$, et al. Consortium on safe Labor. Respiratory morbidity in late preterm births. JAMA 2010;304;419-25. [CrossRef]

22. Kalyoncu Ö, Aygün C, Çetinoğlu E, Küçüködük Ş. Neonatal mortality and morbidity of late preterm babies. J Matern Fetal Neonatal Med 2010;23:607-12. [CrossRef]

23. Anadkat JS, Kuzniewicz MW, Chaudhari BP, Cole FS, Hamvas A. Increased risk for respiratory distress among white, male, late preterm and term infants. J Perinatol 2012;32:780-878. [CrossRef]
24. Wang ML, Dorer DJ, Fleming MP, Catlin EA. Clinical outcomes of near-term infants. Pediatrics 2004;114:372-6. [CrossRef]

25. Teune MJ, Bakhuizen S, Gyamfi Banneman C, Opmeer BC, van Kaam AH, van Wassenaer AG, et al. A Systematic review of severe morbidity in infants born late preterm. Am J Obstet Gynecol 2011;205:374.e 1-9.

26. Laptook A, Jackson GL. Cold stress and hypoglycemia in the late preterm (near term) infant: impact on nursery admission. Semin Perinatol 2006;30:24-7. [CrossRef]

27. Clapp DW. Developmental regulation of the immune system. Semin Perinatol 2006;30:69-72. [CrossRef]

28. Sinha A, Yokoe D, Platt R. Epidemiology of neonatal infections: experience during and after hospitalization. Pediatr Infect Dis $J$ 2003;22:244-51. [CrossRef]

29. Knashu M, Narayaman M, Bhargava S, Oslovich H. Perinatal outcome associated with preterm birth at 33-36 weeks gestation. A population baset cohort study. Pediatrics 2009;123:109-13. [CrossRef]

30. Tomashek KM, Shapiro-Mendoza CK, Weiss J. Early discharge among late preterm and term newborns and risk of neonatal morbidity. Semin Perinatol 2006;30:61-8. [CrossRef]

31. McIntire DD, Leveno KJ. Neonatal mortality and morbidity rates in late preterm births compared with births at term. Obstet Gynecol 2008;111:35-41. [CrossRef]

32. Haroon A, Ali SR, Ahmed S, Maheen H. Short term neonatal outcome in late preterm vs. term infants. J Coll Physicians Surg Pak 2014;24:34-8.

33. Escobar GJ, Clark RH, Greene JD. Short term outcomes of infants born at 35 and 36 weeks gestation: we need to ask more questions. Semin Perinatol 2006;30:28-33. [CrossRef] 